\section{OPEN ACCESS}

Edited by:

Takayuki Yoshimoto,

Tokyo Medical University, Japan

Reviewed by:

Philip Wenzel,

Johannes Gutenberg University

Mainz, Germany

Tomohiro Yoshimoto,

Hyogo College of Medicine, Japan

*Correspondence:

Toshikazu Kondo

kondot@wakayama-med.ac.jp

tThese authors have contributed equally to this work

Specialty section:

This article was submitted to Inflammation,

a section of the journal

Frontiers in Immunology

Received: 23 October 2019 Accepted: 30 December 2019

Published: 07 February 2020

Citation:

Nosaka M, Ishida Y, Kimura $A$ Kuninaka Y, Taruya A, Ozaki M, Tanaka A, Mukaida N and Kondo T (2020) Crucial Involvement of IL-6 in

Thrombus Resolution in Mice via

Macrophage Recruitment and the Induction of Proteolytic Enzymes.

Front. Immunol. 10:3150.

doi: 10.3389/fimmu.2019.03150

\title{
Crucial Involvement of IL-6 in Thrombus Resolution in Mice via Macrophage Recruitment and the Induction of Proteolytic Enzymes
}

\begin{abstract}
Mizuho Nosaka ${ }^{1+}$, Yuko Ishida ${ }^{1 \dagger}$, Akihiko Kimura ${ }^{1}$, Yumi Kuninaka ${ }^{1}$, Akira Taruya ${ }^{2}$, Mitsunori Ozaki ${ }^{3}$, Atushi Tanaka ${ }^{2}$, Naofumi Mukaida ${ }^{4}$ and Toshikazu Kondo ${ }^{1 *}$

${ }^{1}$ Department of Forensic Medicine, Wakayama Medical University, Wakayama, Japan, ${ }^{2}$ Department of Cardiovascular Medicine, Wakayama Medical University, Wakayama, Japan, ${ }^{3}$ Department of Neurological Surgery, Wakayama Medical University, Wakayama, Japan, ${ }^{4}$ Division of Molecular Bioregulation, Cancer Research Institute, Kanazawa University, Kanazawa, Japan
\end{abstract}

After the ligation of the inferior vena cava (IVC) of wild-type (WT) mice, venous thrombi formed and grew progressively until 5 days and resolved thereafter. Concomitantly, intrathrombotic gene expression of $/ / 6$ was enhanced later than 5 days after IVC ligation. IL-6 protein expression was detected mainly in $\mathrm{F} 4 / 80$-positive macrophages in thrombus. When $/ / 6$-deficient $\left(1 / 6^{-/-}\right)$mice were treated in the same manner, thrombus mass was significantly larger than in WT mice. Moreover, the recovery of thrombosed IVC blood flow was markedly delayed in $116^{-1-}$ compared with WT mice. F4/80-positive macrophages in thrombus expressed proteolytic enzymes such as matrix metalloproteinase ( $M m p) 2$, Mmp9, and urokinase-type plasminogen activator (Plau); and their mRNA expression was significantly reduced in $1 / 6^{-/-}$mice. Consistently, the administration of anti-IL-6 antibody delayed the thrombus resolution in WT mice, whereas IL-6 administration accelerated thrombus resolution in WT and $/ 16^{-/-}$mice. Moreover, IL-6 in vitro enhanced Mmp2, Mmp9, and Plau mRNA expression in WT-derived peritoneal macrophages in a dose-dependent manner; and the enhancement was abrogated by a specific Stat3 inhibitor, Stattic. Thus, IL-6/Stat3 signaling pathway can promote thrombus resolution by enhancing Mmp2, Mmp9, and Plau expression in macrophages.

Keywords: IL-6, thrombosis, macrophages, matrix metalloproteinases, proteolytic enzymes

\section{INTRODUCTION}

Deep vein thrombosis (DVT) is a common vascular disease, often causing post-thrombotic symptoms including pain, heaviness, itching, swelling, and brownish or reddish skin discoloration, with ulcer as its long-term complication $(1,2)$. Moreover, DVT is frequently associated with pulmonary embolism (PE), one of the major causes of sudden unexpected natural deaths $(1,2)$. DVT formation has traditionally been thought to be caused by blood stagnancy, endothelial injury of the vein, and hypercoagulability (3). However, evidence is accumulating to indicate the involvement of proinflammatory cytokines and chemokines in the thrombus formation (4-7). Moreover, venous thrombosis resolution and vein wall healing are mediated by leukocytes, particularly macrophages, and their associated chemokines, tissue-type or urokinase-type plasminogen activator (PLAT or PLAU), matrix metalloproteinases (MMPs), and proinflammatory cytokines (8-11). Proinflammatory cytokines 
can potently activate endothelial cells, can increase the expression of adhesion molecules by endothelial cells, and can promote thrombosis $(12,13)$. On the contrary, some chemokines can activate leukocytes to accelerate thrombus resolution and intrathrombotic neovascularization (14-16). We previously demonstrated that a proinflammatory cytokine, IFN- $\gamma$, can decelerate thrombus resolution by suppressing collagenolysis (17). Moreover, the TNF- $\alpha$-TNF-Rp55 axis can promote thrombus resolution by inducing macrophages to express Plau, $M m p 2$, and $M m p$ 9, the proteolytic enzymes that are crucial to collagenolysis and neovascularization (18). However, the roles of other proinflammatory cytokines in DVT formation and/or resolution remain elusive.

IL-6 is a pleiotropic cytokine involved in inflammation, autoantibody production, vascular permeability, tissue regeneration, metabolism, and hematopoiesis. IL-6 is produced by myriads of cells including $\mathrm{T}$ cells, monocytes, fibroblasts, endothelial cells, and keratinocytes (19). IL-6 signaling blockade has recently been proven to be therapeutically effective for a number of autoimmune and inflammatory disorders including rheumatoid arthritis, polymyalgia rheumatica, vasculitis, and Castleman disease, the diseases that exhibit aberrant IL-6 signaling pathway (20). Thrombus forms and resolves with distinct phases consisting of neutrophil and macrophage infiltration, fibrosis, and neovascularizationinduced recanalization $(14,21)$; and the whole process resembles skin wound healing process. We previously revealed that $I 6^{-/-}$ mice exhibited delayed skin wound healing with attenuated leukocyte infiltration, re-epithelialization, angiogenesis, and collagen accumulation (22). Thrombus formation and resolution processes share with skin wound healing processes various pathophysiological aspects such as leukocyte accumulation, collagen production, and angiogenesis. This promoted us to conduct our previous study, which revealed markedly enhanced IL-6 protein in thrombi of wild-type (WT) mice (23). However, the pathophysiological roles of IL-6 in venous thrombosis are still unknown.

In this study, we demonstrated that the absence of IL- 6 did retard thrombus resolution, together with suppressed expression of MMP-2, MMP-9, and PLAT, compared with that in WT mice. This mirrors the observation that IL- 6 could enhance the gene expression of Plau, Mmp2, and Mmp9 in macrophages in an IL-6dependent manner. These observations implied that the IL- 6 can be a target molecule to design the therapeutic strategy for DVT.

\section{MATERIALS AND METHODS}

\section{Reagents and Antibodies}

Recombinant murine IL-6 (rIL-6) and anti-mouse IL-6 monoclonal antibody ( $\mathrm{mAb}$ ) were purchased from PeproTech (London, UK) and R\&D Systems (Minneapolis, MN), respectively. Stattic, a STAT3 inhibitor V, was obtained from Calbiochem (Billerica, MA). The following $\mathrm{mAbs}$ and

Abbreviations: DVT, deep vein thrombosis; IVC, inferior vena cava; MMP, matrix metalloproteinase; PE, pulmonary embolism; Plau, urokinase-type plasminogen activator. polyclonal Abs (pAbs) were used for immunohistochemical and double-color immunofluorescence analyses: rat anti-mouse F4/80 mAb (Dainippon Pharmaceutical Company, Japan), mouse anti-IL-6 mAb (Santa Cruz Biotechnology, Dallas, Texas), rabbit anti-mouse IL-6 pAbs, rabbit anti-mouse CCL2 pAbs (Novus Biologicals, Centennial, CO), goat anti-mouse MMP-2 pAbs, goat anti-mouse MMP-9 pAbs (Santa Cruz Biotechnology, Dallas, Texas), rabbit anti-mouse PLAU (uPA) pAbs, rabbit anti-mouse tPA pAbs, rabbit anti-mouse PAI-1 pAbs (Santa Cruz Biotechnology, Dallas, TX), mouse anti-mouse Col1A2 mAb (Santa Cruz Biotechnology), rabbit anti-mouse myeloperoxidase (MPO) pAbs (Neomarkers, Fremont, CA), rabbit anti-mouse CD3 mAb (Abcam, Tokyo, Japan), cyanine dye 3-conjugated donkey anti-rat IgG pAbs, cyanine dye 3-conjugated donkey anti-goat IgG, fluorescein isothiocyanate (FITC)-conjugated donkey anti-rat IgG pAbs, and FITC-conjugated donkey antirabbit IgG pAbs (Jackson ImmunoResearch Laboratories, West Grove, PA). A Western blot analysis was performed by using the following Abs: rabbit anti-mouse Stat $3 \mathrm{mAb}$, rabbit anti-mouse phosphorylated (p)-Stat3 mAb, rabbit anti-mouse p38 MAPK pAbs, rabbit anti-mouse JNK pAbs, rabbit anti-mouse ERK mAb, rabbit anti-mouse p-p38 MAPK mAb, rabbit anti-mouse p-JNK pAbs, rabbit anti-mouse $\mathrm{p}$-ERK $\mathrm{mAb}$, and rabbit anti-GAPDH mAb (Cell Signaling Technology, Danvers, MA).

\section{Mice}

Pathogen-free male BALB/c mice that are 8-10 weeks old were obtained from Japan SLC (Shizuoka, Japan) and were designated as WT mice in this study. $I l 6^{-/-}$mice were a kind gift of Dr. Blüthmann (24) and were back-crossed to BALB/c mice for more than 10 generations. Subsequently, age- and sexmatched $I l 6^{-/-}$mice were used in these experiments (25). All mice were housed individually in cages under specific pathogenfree conditions during the experiments. All animal experiments were approved by the Committee on Animal Care and Use in Wakayama Medical University and complied with the Guidelines for the Care and Use of Laboratory Animals of Wakayama Medical University.

\section{Inferior Vena Cava Ligation-Induced Deep Vein Thrombus Model}

Intravenous thrombus formation was induced as previously described $(14,17,26)$. In brief, after deep anesthesia with intraperitoneal injection of pentobarbital $(50 \mathrm{mg} / \mathrm{kg}$ of body weight), a $2-\mathrm{cm}$ incision was made along the abdominal midline. Then, inferior vena cava (IVC) was exposed carefully, and a 21gauge needle was placed along the exposed IVC. Subsequently, IVC was ligated with the needle using 3-0 silk suture, followed by pulling out the needle. This procedure can induce thrombus formation in almost all the mice. In some experiments, WT mice were intraperitoneally given anti-mouse IL- $6 \mathrm{mAb}[5 \mu \mathrm{g} /$ mouse in $200 \mu$ l of phosphate-buffered saline (PBS)] at 1,3,6, and 8 days after IVC ligation. WT and $I l 6^{-/-}$mice were intraperitoneally given rIL-6 (0.3 $\mu \mathrm{g} /$ mouse in $200 \mu \mathrm{l}$ of PBS) at 1, 4, and 8 days after IVC ligation. At the indicated time intervals after the IVC ligation, mice were euthanized by an overdose of diethyl ether, 
and intravenous thrombi were harvested for the determination of the weights.

\section{Histopathological Analyses}

At the indicated time intervals after IVC ligation, thrombi were harvested and fixed in $4 \%$ formaldehyde buffered with PBS ( $\mathrm{pH}$ 7.2), and paraffin-embedded sections ( $4 \mu \mathrm{m}$ thick) were made. The sections were stained with hematoxylin and eosin (H\&E) or Masson trichrome solution.

\section{Immunohistochemical Analyses}

Deparaffinized sections were immersed in $0.3 \% \mathrm{H}_{2} \mathrm{O}_{2}$ in methanol for $30 \mathrm{~min}$ to eliminate endogenous peroxidase activities. The sections were further incubated with PBS containing $1 \%$ normal serum derived from the same species as the origin of the secondary Abs and $1 \%$ bovine serum albumin (BSA) to reduce non-specific reactions. The sections were incubated with anti-mouse F4/80 mAb, anti-mouse CCL2 pAbs, anti-mouse Col1A2 mAb, anti-mouse MPO pAbs, antimouse CD3 mAb, or anti-mouse IL- 6 pAbs at a concentration of $1 \mu \mathrm{g} / \mathrm{ml}$ at $4^{\circ} \mathrm{C}$ overnight. After the incubation of biotinylated secondary Abs, immune complexes were visualized using Catalyzed Signal Amplification System (Dako) according to the manufacturer's instructions.

\section{Measurements of Intrathrombotic Leukocytes}

Intrathrombotic macrophage and CCL2-positive cell numbers were determined as previously described $(17,18)$. Briefly, after F4/80-positive macrophages, MPO-positive neutrophils, or CCL2-positive cells were counted in five high power fields $(\times 1,000)$ within the thrombus, the total numbers in the five fields were combined. All measurements were performed by an examiner without a prior knowledge of the experimental procedures.

\section{Double-Color Immunofluorescence Analyses}

Deparaffinized sections were incubated with PBS containing $1 \%$ normal donkey serum and $1 \%$ BSA to reduce nonspecific reactions as previously described (17). Thereafter, the sections were further incubated with the combinations of anti-F4/80 and anti-IL-6, anti-MMP-2, anti-MMP-9, or anti-PLAU (uPA); anti-MPO and anti-IL-6; or anti-CD3 and anti-IL-6. All Abs were used at a concentration of $1 \mu \mathrm{g} / \mathrm{ml}$. After the incubation with fluorochrome-conjugated secondary Abs $(15 \mu \mathrm{g} / \mathrm{ml})$ at room temperature for $30 \mathrm{~min}$, the sections were observed under a fluorescence microscopy. In some experiments, nuclei were stained using 4',6-diamidino2-phenylindole (DAPI; Roche Diagnostics, Indianapolis, IN) according to the manufacturer's instructions.

\section{Inferior Vena Cava Blood Flow Measurement by Laser Doppler Flowmeter}

At 5, 10, and 14 days after IVC ligation, microvascular IVC blood flow was evaluated by laser Doppler imaging (OMEGAFLO FLOC1 BV, OMEGAWAVE) as described previously (17). Blood flow through the exposed IVC region of the interest was assessed at three time points; immediately after laparotomy, at the indicated time points after the ligation, and at the harvest. The intensities were reported as the percentage of the baseline blood flow of each animal, in order to ensure consistency.

\section{Extraction of Total RNAs and Real-Time Reverse Transcription-PCR}

Real-time reverse transcription (RT)-PCR was performed as described previously (17). Briefly, total RNAs were extracted from tissue samples $(100 \mu \mathrm{g})$ using ISOGENE (Nippon Gene, Toyama, Japan) according to the manufacturer's instructions, and $5 \mu \mathrm{g}$ of total RNAs were reverse-transcribed into cDNA at $42^{\circ} \mathrm{C}$ for $1 \mathrm{~h}$ in $20 \mu \mathrm{l}$ of reaction mixture containing mouse Moloney leukemia virus reverse transcriptase (PrimeScript, Takara Bio, Kusatsu, Japan) with random 6 primers (Takara Bio). Thereafter, generated cDNA was subjected to a real-time PCR analysis using SYBR ${ }^{\circledR}$ Premix Ex Taq $^{\mathrm{TM}}$ II kit (Takara Bio) with the sets of specific primers (Table 1). Relative quantity of the target gene expression to $A c t b$ gene was measured by comparative Ct method.

\section{ELISA for IL-6}

At the indicated time intervals, thrombus samples were obtained and homogenized with $0.3 \mathrm{ml}$ of PBS ( $\mathrm{pH} 7.2$ ) containing complete Protease Inhibitor Cocktail (Roche Diagnostics). The homogenates were centrifuged at 12,000 g for $15 \mathrm{~min}$. IL-6 levels in the supernatant were measured using a specific ELISA kit (Murine IL-6 ELISA kit, Diaclone, Besancon Cedex, France), according to the manufacturer's instructions. The detection limit was $10 \mathrm{pg} / \mathrm{ml}$. Total protein in the supernatant was measured with a commercial kit (BCA Protein Assay Kit; Pierce) using BSA as a standard. The data were expressed as IL-6 (ng/ml)/total protein $(\mathrm{mg} / \mathrm{ml})$ for each sample.

TABLE 1 | Sequences of the primers used for real-time RT-PCR.

\begin{tabular}{|c|c|}
\hline Transcript & Sequence \\
\hline \multirow[t]{2}{*}{$1 / 6$} & (F) 5'-CCACTTCACAAGTCGGAGGCTTA-3' \\
\hline & (R) 5'-GCAAGTGCATCATCGTTGTTCATAC-3' \\
\hline \multirow[t]{2}{*}{ Col1 } & (F) 5'-ATGCCGCGACCTCAAGATG-3' \\
\hline & (R) 5'-TGAGGCACAGACGGCTGAGTA-3' \\
\hline \multirow[t]{2}{*}{ Mmp2 } & (F) 5'-GATAACCTGGATGCCGTCGTG-3' \\
\hline & (R) 5'-CTTCACGCTCTTGAGACTTTGGTTC-3' \\
\hline \multirow[t]{2}{*}{ Mmp9 } & (F) 5'-GCCCTGGAACTCACACGACA-3' \\
\hline & (R) 5'-TTGGAAACTCACACGCCAGAAG-3' \\
\hline \multirow[t]{2}{*}{ Plau } & (F) 5'-GAGCAGCTCATCTTGCACGAATAC-3' \\
\hline & (R) 5'-GCCAGTGATCTCACAGTCTGAACC-3' \\
\hline \multirow[t]{2}{*}{ Ccl2 } & (F) 5'-GCATCCACGTGTTGGCTCA-3' \\
\hline & (R) 5'-CTCCAGCCTACTCATTGGGATCA-3' \\
\hline \multirow[t]{2}{*}{ Actb } & (F) 5'-CATCCGTAAAGACCTCTATGCCAAC-3' \\
\hline & (R) 5'-ATGGAGCCACCGATCCACA-3' \\
\hline
\end{tabular}

$F$, forward primer; $R$, reverse primer; $R T$, reverse transcription. 


\section{Cell Culture}

WT mice were i.p. injected with $2 \mathrm{ml}$ of $3 \%$ thioglycollate (Sigma-Aldrich), to obtain intraperitoneal macrophages 3 days later as described previously (17). The obtained cells were judged to consist of more than $95 \%$ macrophages as determined by flowcytometry (FCM) using anti-F4/80 Ab. The resultant cells were suspended in antibiotic-free Roswell Park Memorial Institute (RPMI) 1640 medium containing 10\% fetal bovine serum (FBS) and incubated at $37^{\circ} \mathrm{C}$ in three 6-well cell culture plates. $2 \mathrm{~h}$ later, non-adherent cells were removed, and the medium was replaced. After the cells were incubated for $24 \mathrm{~h}$ in the presence of the indicated concentrations of rIL$6(1,000 \mathrm{U} / \mathrm{ml})$, together with or without anti-mouse IL-6 $\mathrm{mAb}(5 \mu \mathrm{g} / \mathrm{ml})$, or Stattic $(20 \mu \mathrm{M})$, the cells were subjected to subsequent analyses.

\section{Western Blotting}

The obtained macrophages were homogenized with a lysis buffer [20 mM of Tris- $\mathrm{HCl}$ ( $\mathrm{pH} 7.6$ ), $150 \mathrm{mM}$ of $\mathrm{NaCl}, 1 \%$ Triton X-100, and $1 \mathrm{mM}$ of EDTA] containing complete Protease Inhibitor Cocktail (Roche Diagnostics) and were centrifuged to obtain lysates. The lysates (equivalent to $30 \mu \mathrm{g}$ of protein) were electrophoresed in a $10 \%$ sodium dodecyl sulfate (SDS)-polyacrylamide gel and were transferred onto a nylon membrane. After the membrane was sequentially reacted with optimally diluted primary Abs and horseradish peroxidase (HRP)-conjugated secondary Abs, the immune complexes were visualized using ECL system (Amersham Biosciences, Pittsburgh, $\mathrm{PA}$ ). The band intensities were measured using $\mathrm{NIH}$ Image Analysis Software version 1.48 (National Institutes of Health).

\section{Measurement of Prothrombin Time and Activated Partial Thromboplastin Time}

Blood samples were taken with $3.8 \%$ citrate solution and centrifuged to obtain plasma samples. Prothrombin time (PT) and activated partial thromboplastin time (APTT) of citrated plasma samples were measured by using COAGSEARCH (A\&T) according to the manufacturer's instructions.

\section{Statistical Analyses}

Data were expressed as the mean \pm SEM. For the comparison between WT and $16^{-/-}$mice at multiple time points, a twoway ANOVA followed by Dunnett's post-hoc test was used. To compare the values between two groups, unpaired Student's $t$ test was performed. In the series of IL- 6 stimulation on peritoneal macrophages in vitro, a one-way ANOVA followed by Dunnett's post-hoc test was used. $p<0.05$ was considered statistically significant. All statistical analyses were performed using Statcel3 software under the supervision of a medical statistician.

\section{RESULTS}

\section{Intrathrombotic IL-6 Expression After the Inferior Vena Cava Ligation}

The detection of IL- 6 in venous thrombi in autopsy cases (our unpublished data) prompted us to examine intrathrombotic gene expression of Il6 in WT mice after IVC ligation. Il6 mRNA was detected in the thrombus 5 days after IVC ligation, and its expression was decreased later than 10 days (Figure 1A). Consistently, IL-6 protein could be detected at day 5 and later (Figure 1B). IL-6 protein was immunohistochemically found in macrophage-like cells inside thrombus (Figure 1C). Consistently, double-color immunofluorescence analyses identified $\mathrm{F} 4 / 80^{+}$macrophages but not $\mathrm{MPO}^{+}$neutrophils and $\mathrm{CD}^{+} \mathrm{T}$ cells as a main cellular source of IL-6 (Figure 1D and Figure S1). Thus, these observations would imply the involvement of macrophage-derived IL-6 in the formation and/or resolution of deep vein thrombi.

\section{Impaired Thrombus Resolution in the Absence of IL-6}

In order to explore the pathophysiological roles of IL-6 in IVC ligation-induced venous thrombus, we compared thrombus formation between WT and $I 6^{-/-}$mice. At 5 days after IVC ligation, $I l 6^{-/}$mice developed a larger thrombus than did WT mice (Figures 2A,B). However, WT and $\mathrm{Il6}^{-/-}$mice exhibited similar coagulation functions as revealed by PT (WT, $9.68 \pm$ $0.27 \mathrm{~s}$ vs. $\mathrm{Il}^{-/-}, 9.46 \pm 0.43 \mathrm{~s}$ ) and APTT (WT, $36.88 \pm 0.66 \mathrm{~s}$ vs. $\left.I 6^{-/-}, 34.91 \pm 2.38 \mathrm{~s}\right)$. On the contrary, intrathrombotic collagen areas were remarkably enhanced in $\mathrm{Il6}^{-/-}$mice compared with WT mice as revealed by both Masson staining and immunostaining for Col1A2 (Figures 2C,D). Consistently, at 10 and 14 days after IVC ligation, intrathrombotic Col1 mRNA expression was significantly higher in $\mathrm{Il6}^{-/-}$mice than WT mice (Figure 2E), indicating that the thrombus in $I 6^{-/-}$ mice was replaced with collagen to a larger extent than that in WT mice. Mirroring collagen contents in thrombus, blood flow recovery was delayed in $I 6^{-/-}$mice compared with WT mice (Figure 2F). Collectively, these observations implied that the lack of IL- 6 could retard thrombus resolution with excessive collagen deposition.

\section{Reduced Intrathrombotic Macrophage Infiltration With Attenuated CCL2 Expression}

Accumulating evidence implicated the crucial roles of infiltrating macrophages in thrombus resolution $(27,28)$. F4/80-positive macrophages infiltrated into thrombus in WT and $I l 6^{-/-}$mice, reaching a maximal level at 7 days and decreasing thereafter, but intrathrombotic macrophage numbers were larger in WT mice than $I l 6^{-/-}$mice (Figures $3 \mathbf{A}, \mathbf{B}$ ). CCL2 is a potent chemotactic cytokine for the intrathrombotic recruitment of monocytes/macrophages via CCR2 (14). Hence, we examined intrathrombotic CCL2 expression in WT and $I l 6^{-/-}$mice. The intrathrombotic expression of $\mathrm{Ccl} 2 \mathrm{mRNA}$ was up-regulated in WT mice at 5 days after IVC ligation, whereas the enhancement was significantly attenuated in $\mathrm{Il6}^{-/-}$mice (Figure 3C). Moreover, immunohistochemical analyses demonstrated that the intrathrombotic CCL2-positive cell numbers were significantly lower at 5 and 10 days after IVC ligation in $\mathrm{Il6}^{-/-}$mice than in WT mice (Figures 3D,E). Thus, the lack of IL-6 reduced intrathrombotic macrophage infiltration with attenuated CCL2 expression. 

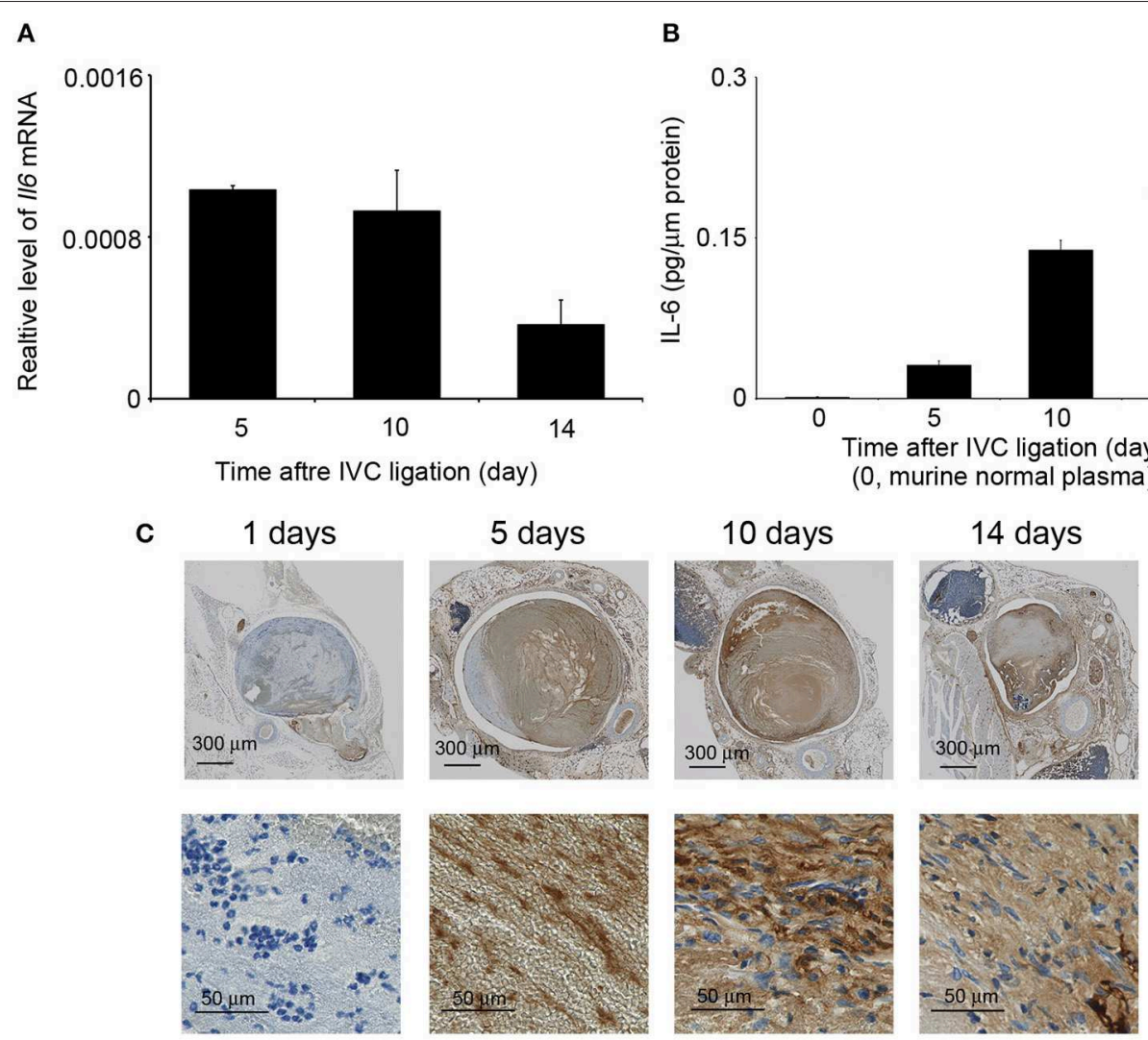

C
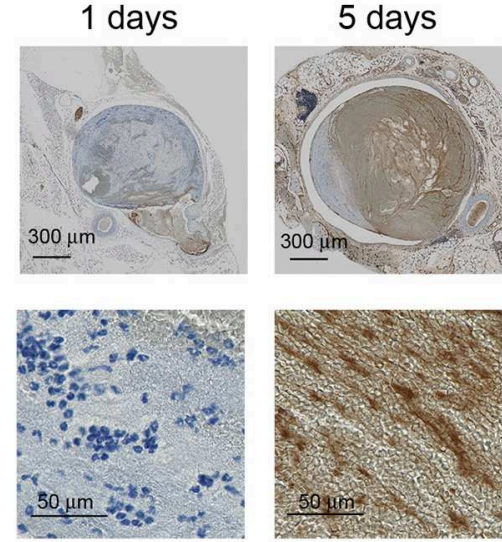

D
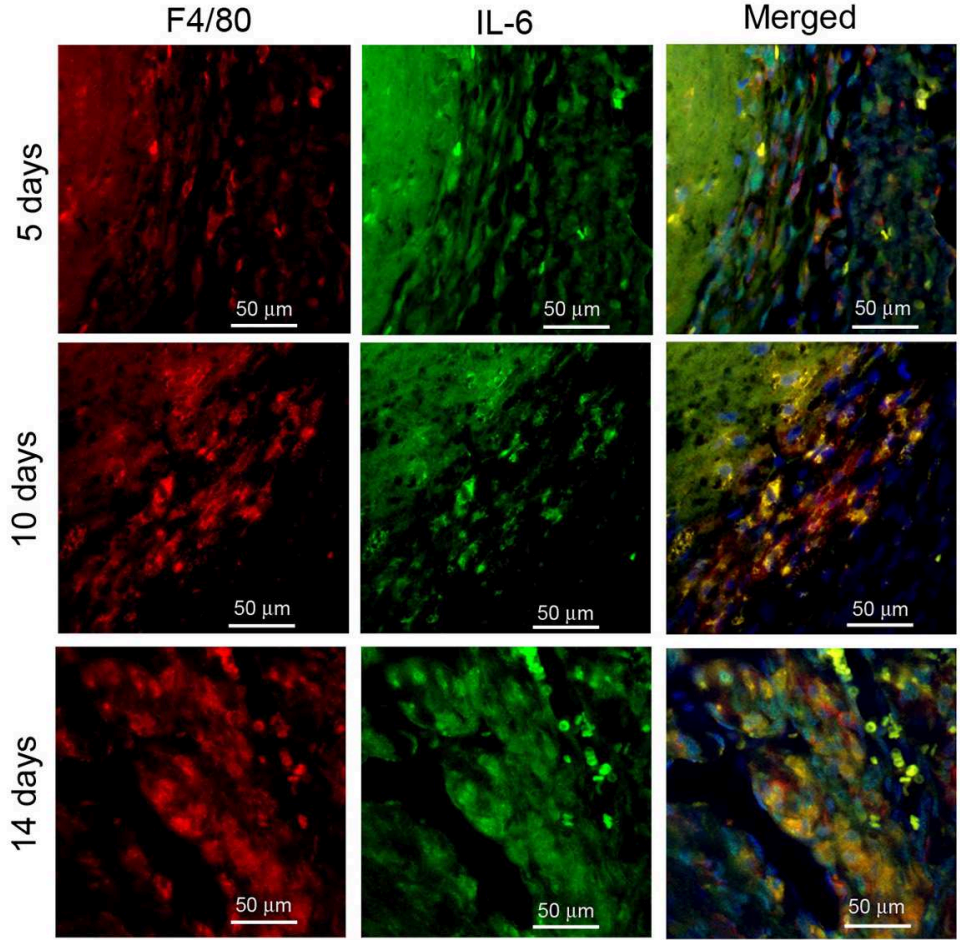

FIGURE 1 | Intrathrombotic expression of IL-6 in wild-type (WT) mice after inferior vena cava (IVC) ligation. (A) //6 gene expression was examined by real-time reverse transcription (RT)-PCR as described in section Materials and Methods. All values represent mean \pm SEM $(n=6)$. (B) Intrathrombotic IL-6 protein levels were determined by ELISA. All values represent mean \pm SEM $(n=6)$. (C) Immunohistochemical analysis of intrathrombotic IL-6 expression (original magnification, $\times 100$ 
FIGURE 1 | upper panel; ×400, lower panel). (D) A double-color immunofluorescence analysis of IL-6-expressing cells in the thrombus. The samples were immunostained with the combination of anti-F4/80 mAb and anti-IL-6 pAbs as described in section Materials and Methods. The fluorescent images were digitally merged in the right panel. Representative results from six independent experiments are shown here [original magnification, $\times 400$; blue, nuclear staining by 4',6-diamidino-2-phenylindole (DAPI)].

\section{Reduced Expression of Macrophage-Derived Proteolytic Enzymes in the Absence of IL-6}

We previously revealed that intrathrombotic macrophages were a major source of proteolytic enzymes such as MMP-2, MMP9, and PLAU, which were essentially involved in thrombus resolution $(17,18)$. Consistent with our previous reports $(17,18)$, double-color immunofluorescence analyses revealed that intrathrombotic F4/80-positive macrophages were a main cellular source of MMP-2, MMP-9, and PLAU (Figures 4A-C). Furthermore, later than 10 days after IVC ligation, when thrombus resolution started, mRNA expression of $M m p 2$, $M m p 9$, and Plau was markedly enhanced in thrombus in WT mice, whereas the increments were significantly depressed in $I l 6^{-/-}$mice compared with WT mice (Figures $4 \mathrm{D}-\mathrm{F}$ ). These observations would indicate that delayed thrombus resolution in $I l 6^{-/-}$mice can be ascribed to depressed expression of Mmp2, $M m p 9$, and Plau, the proteolytic enzymes that were expressed mainly by intrathrombotic macrophages.

\section{Effects of Anti-IL-6 Antibody and Recombinant IL-6 on Thrombus Resolution}

We next examined the effects of anti-IL- $6 \mathrm{mAb}$ and rIL- 6 on the resolution of IVC ligation-induced venous thrombi. Anti-IL-6 $\mathrm{mAb}$ significantly increased thrombus weights and decelerated blood flow recovery compared with those in control Abtreated mice, together with depressed intrathrombotic $M m p 2$, Mmp9, and Plau gene expression (Figures 5A-F), similarly as observed in $\mathrm{Il}^{-/-}$mice. On the contrary, when rIL-6 administration started 1 day after IVC ligation, it reduced significantly the thrombus weights and accelerated blood flow recovery with increased intrathrombotic $M m p 2, M m p 9$, and Plau gene expression in WT (Figures 5G-L), but without any significant effects on coagulation tests (PT in WT mice: PBS, $9.74 \pm 0.28$ s vs. rIL-6, $9.85 \pm 0.31$ s; APTT in WT mice: PBS, $36.6 \pm 0.27 \mathrm{~s}$ vs. rIL-6, $37.8 \pm 3.08 \mathrm{~s}$ ). These observations would indicate that IL- 6 could be therapeutically effective for thrombus formation at least at its early stage. Moreover, supplementation of IL-6 reduced thrombus weights and enhanced blood flow recovery in $\mathrm{Il}^{-/-}$mice (Figure S2). These observations would indicate that IL-6 could regulate the thrombosis resolution without affecting coagulation activities.

\section{The Effects of IL-6 on Gene Expression of Mmp2, Mmp9, and Plau in Macrophages}

Depressed intrathrombotic Mmp2, Mmp9, and Plau expression in $I l 6^{-/-}$mice prompted us to examine the effects of IL- 6 on the gene expression of Mmp2, Mmp9, and Plau mRNA expression in WT-derived macrophages. IL-6 significantly enhanced $M m p 2$, Mmp9, and Plau mRNA expression in macrophages in a dose-dependent manner (Figures 6A-C). These observations indicated that IL-6-medicated signals regulated Mmp2, Mmp9, and Plau gene expression in macrophages. Moreover, IL-6 increased significantly phosphorylation of Stat3 (Figures 6D,E), but not that of ERK, p38, and JNK in macrophages (Figure S3). Hence, we further examined the effects of a specific Stat3 inhibitor, Stattic, on IL-6-mediated increases in Mmp2, Mmp9, and Plau gene expression in macrophages. Stattic abrogated IL-6induced increases in Mmp2, Mmp9, and Plau mRNA expression similarly as anti-IL-6 antibody did (Figures 6F-H). Collectively, IL-6 could induce the expression of Mmp2, Mmp9, and Plau in macrophages through Stat3 pathway.

\section{DISCUSSION}

Accumulating evidence implicates IL-6 as a key regulator of several inflammatory diseases (19). Consistently, we previously revealed that the lack of IL- 6 decelerated skin wound healing with a concomitant reduced leukocyte accumulation and collagen deposition (22). Skin wound healing and thrombus resolution share several pathophysiological features: initial platelet aggregation, subsequent leukocyte infiltration, and collagen deposition (26), and final neovascularization. These shared features prompted us to investigate the roles of IL-6 in thrombus formation and resolution. Actually, macrophages were a major source of IL-6 in thrombus, and $I 6^{-/-}$mice exhibited retarded thrombus resolution as evidenced by larger venous thrombi similarly as observed in skin wound healing sites. However, $\mathrm{Il6}^{-/-}$mice exhibited increased intrathrombotic collagen contents than did WT mice, suggesting that IL-6 may have distinct roles between skin wound healing and thrombus resolution, in terms of collagen accumulation in the lesions.

Accumulating evidence revealed that various types of leukocytes were crucially involved in thrombus resolution. Neutrophil depletion impaired thrombus resolution (27), whereas intrathrombus injection of peritoneal macrophages accelerated thrombus resolution (28). Moreover, Luther and colleagues demonstrated that the absence of effector memory $\mathrm{T}$ cells accelerated thrombus resolution (29). In line with these observations, we previously revealed the potential contribution of intrathrombotic leukocyte accumulation to thrombus resolution (30). Consistently, $\mathrm{Il}^{-/-}$mice exhibited reduced neutrophil (Figure S3) and macrophage accumulation after IVC ligation than did WT mice. Thus, the depressed leukocyte infiltration may contribute to delayed thrombus resolution in Il6 ${ }^{-/-}$mice.

Chemokine system, a major controller of leukocyte trafficking, can also regulate thrombus formation and resolution by manipulating the migration of leukocytes, key players in the processes (31). This notion was substantiated by the 

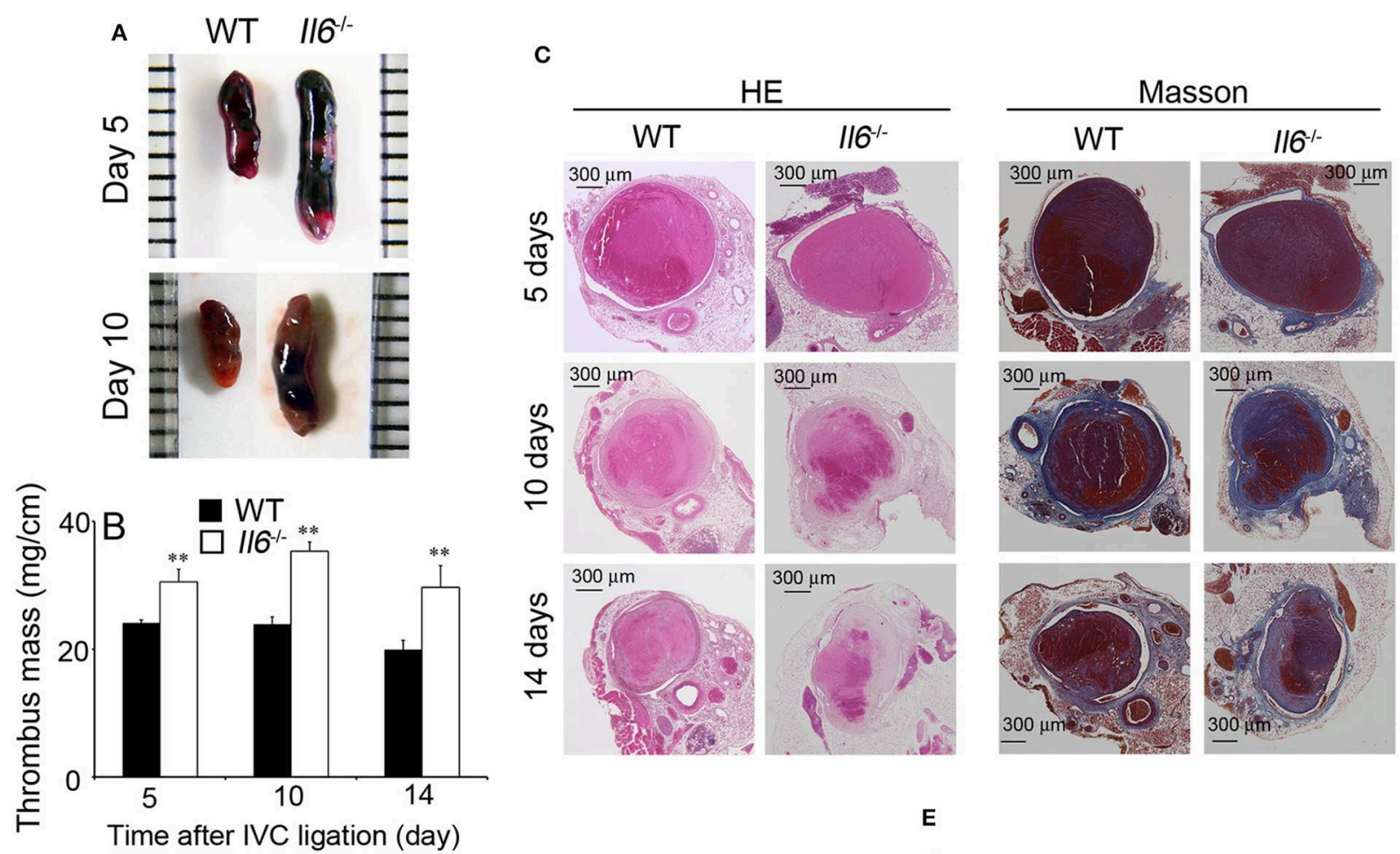

D

WT
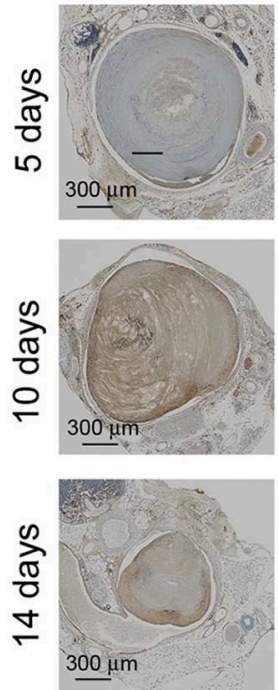
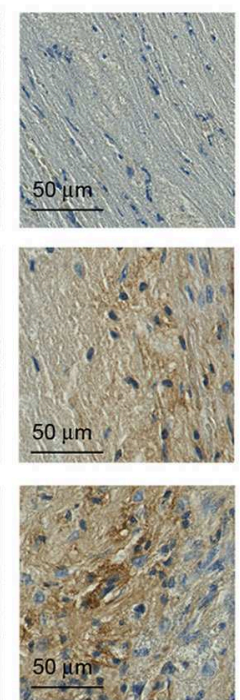

$116^{-1-}$
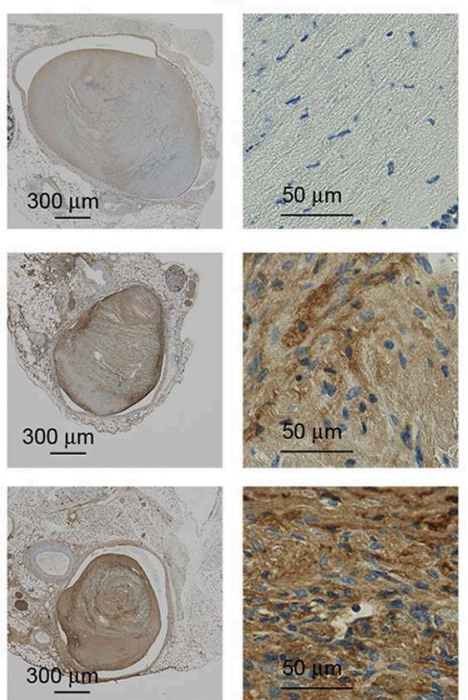
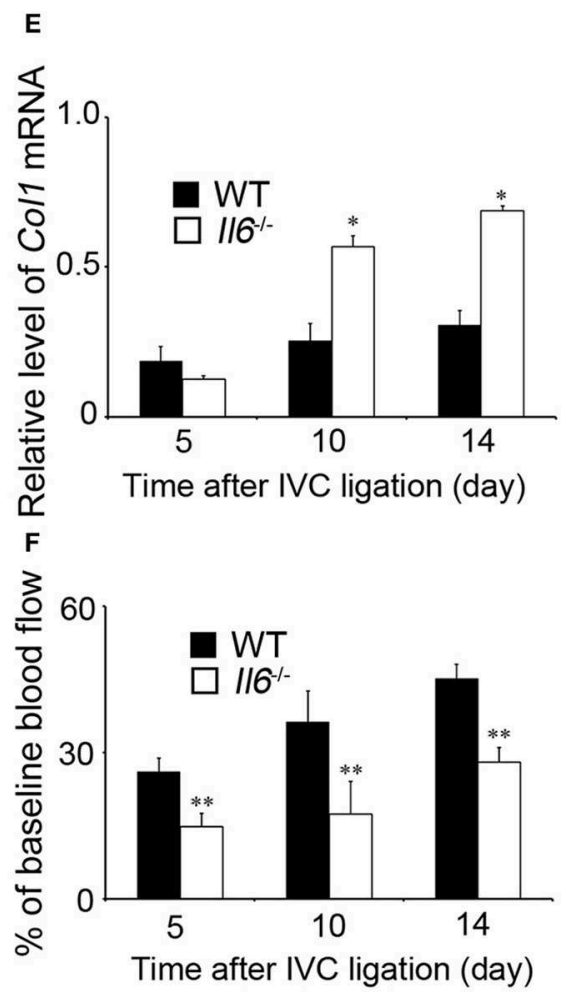

FIGURE 2 | Inferior vena cava (IVC) ligation-induced deep vein thrombus formation in wild-type (WT) and //6 ${ }^{-/-}$mice. (A) Macroscopic appearance of venous thrombi in WT and $/ / 6^{-/-}$mice at 5 and 10 days after IVC ligation. Representative results from six independent animals are shown here. (B) Thrombus mass of WT and $/ / 6^{-/-}$ mice at the indicated time intervals after IVC ligation. All values represent the mean \pm SEM $(n=6)$. ${ }^{* *} p<0.01$, WT vs. I/6 ${ }^{-/-}$. (C) Histopathological analyses of venous thrombi obtained from WT and $/ 16^{-/-}$mice at 5, 10, and 14 days after IVC ligation. Venous thrombi were stained with hematoxylin and eosin (H\&E) or Masson trichrome solution (Masson). Representative results from six independent experiments are shown here (original magnification, $\times 100)$. (D) Immunohistochemical detection of Col1A2 proteins in the thrombi obtained from WT and $/ / 6^{-/-}$mice at 5, 10, and 14 days after IVC ligation. (E) Intrathrombotic Co/1 gene expression in WT and $/ / 6^{-/-}$mice at the indicated time intervals after IVC ligation. All values represent the mean \pm SEM $(n=6){ }^{*} p<0.05$, WT vs. $/ / 6^{-/-}$. (F) Laser Doppler analysis of thrombosed blood flow. All values represent the values mean \pm SEM ( $n=6$ animals). ${ }^{* *} p<0.01$, WT vs. $/ 16^{-/-}$. 
A

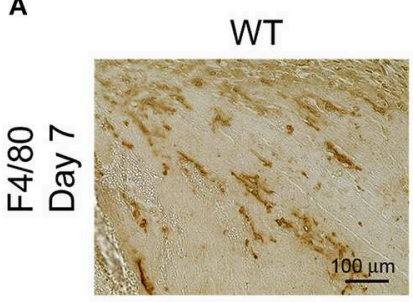

$116^{-1-}$

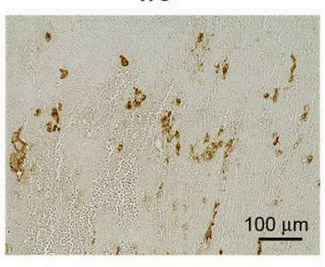

C
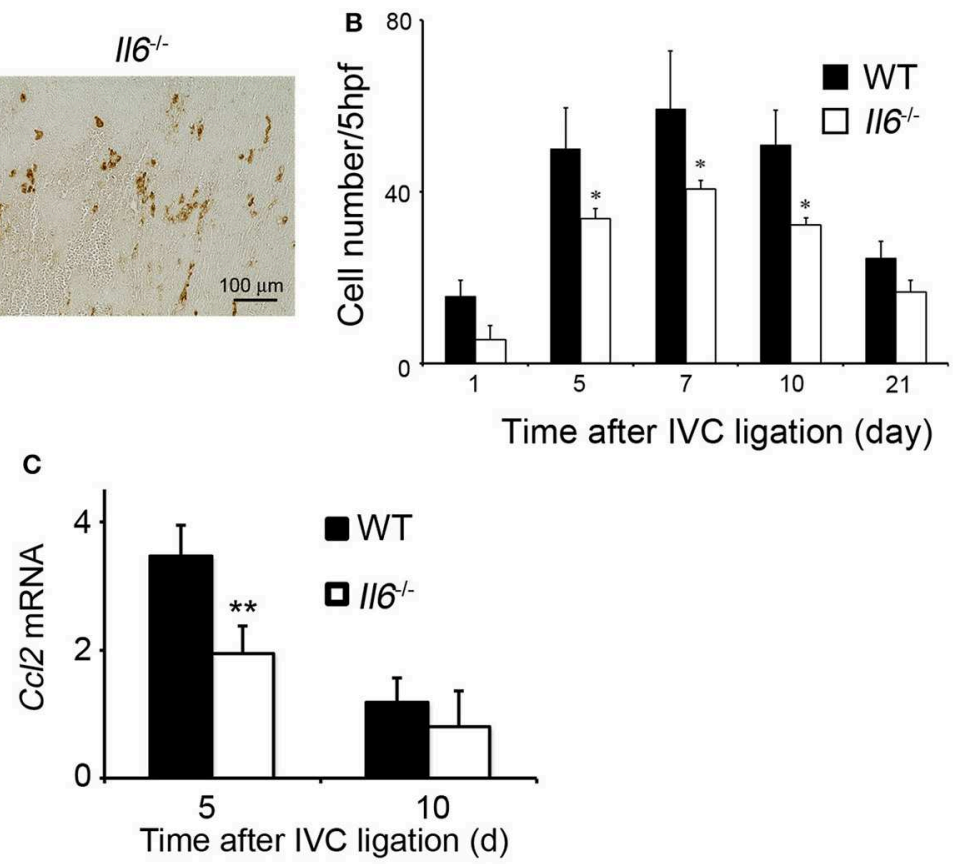

D

WT
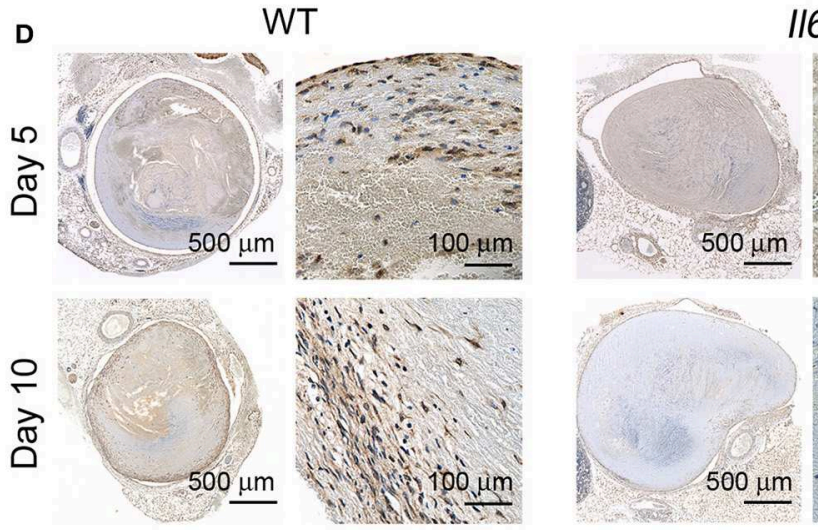

$116^{-1-}$

E

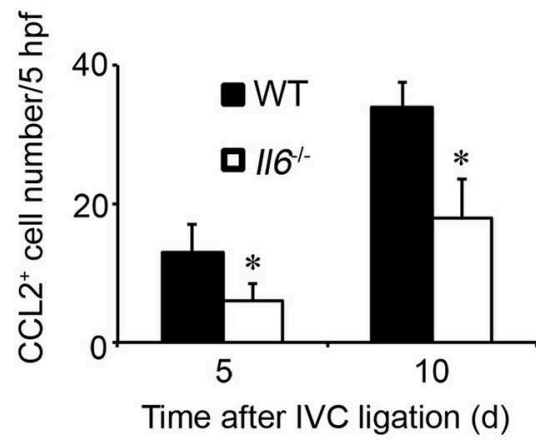

FIGURE 3 | The effects of IL-6 deficiency on macrophage infiltration and CCL2 expression in thrombus tissues. (A) Immunohistochemical analysis was performed using anti-F4/80 mAb at day 5 in venous thrombus samples from wild-type (WT) and I/6-/- mice (original magnification, $\times 400$ ). Representative results from six independent experiments are shown here. (B) F4/80-positive macrophage numbers were determined as described in section Materials and Methods. All values represent the mean \pm SEM ( $n=6$ animals). ${ }^{*} p<0.05$, WT vs. II6-/- (C) Intrathrombotic expression of Ccl2 mRNA after inferior vena cava (IVC) ligation was determined by real-time reverse transcription (RT)-PCR as described in section Materials and Methods. All values represent the mean \pm SEM ( $n=6$ animals). ${ }^{* *} p<0.01$, WT vs. $116^{-/-}$. (D) Immunohistochemical analyses of intrathrombotic CCL2. Representative results from six independent experiments are shown here. (E) Intrathrombotic CCL2-positive cell numbers were determined. All values represent the mean \pm SEM. ${ }^{*} p<0.05$, WT vs. I/6 ${ }^{-1-}$. 

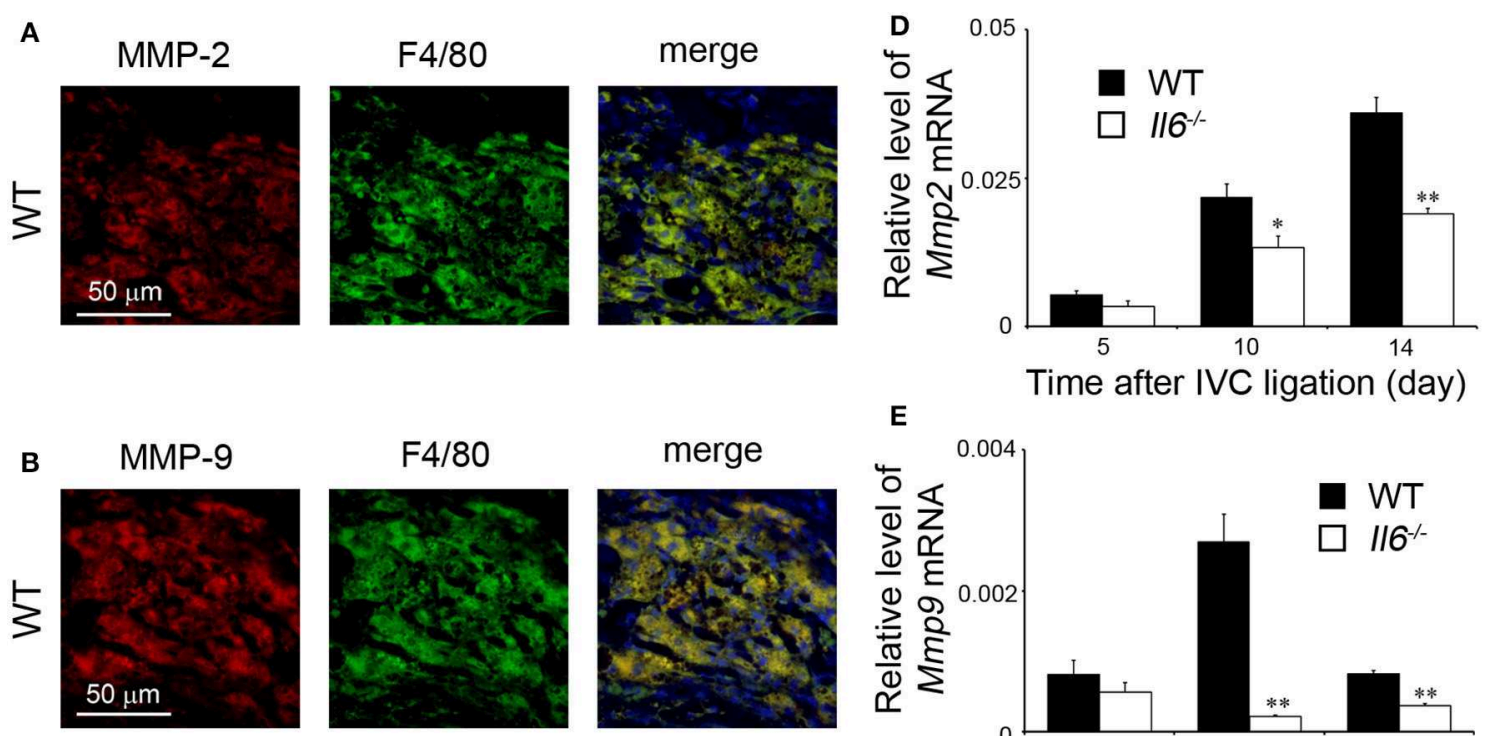

Time after IVC ligation (day)

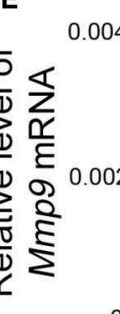

$\mathbf{F}$

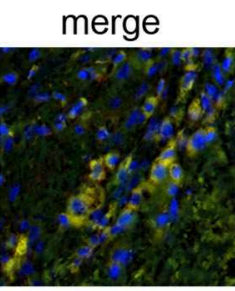

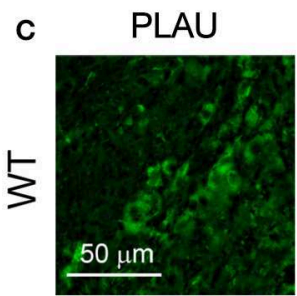

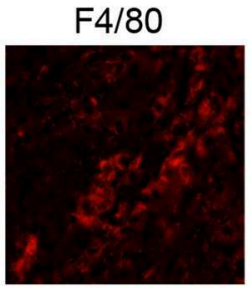

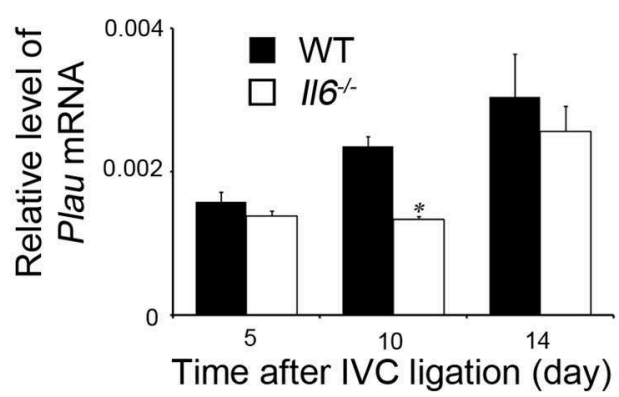

FIGURE 4 | Intrathrombotic expression of proteolytic enzymes in wild-type (WT) and //6 $6^{-1-}$ mice. (A-C) A double-color immunofluorescence analysis of MMP-2-, MMP-9-, or PLAU-expressing cells in the thrombus. The fluorescent images were digitally merged in the right panel. Representative results from six independent experiments are shown here [original magnification, $\times 400$; blue, nuclear staining by 4',6-diamidino-2-phenylindole (DAPI)]. (D-F) Intrathrombotic gene expression of Mmp2 (D), Mmp9 (E), and Plau (F) after inferior vena cava (IVC) ligation. Each gene expression was determined by real-time reverse transcription (RT)-PCR as described in section Materials and Methods. All values represent the mean \pm SEM ( $n=6$ animals). ${ }^{*} p<0.05,{ }^{* *} p<0.01$, WT vs. $/ / 6^{-/-}$.

observations that the administration of exogenous MCP1/CCL2, a potent macrophage chemoattractant, accelerated venous thrombus resolution together with enhanced $\mathrm{F} 4 / 80^{+}$ macrophage infiltration (16). Consistently, the genetic deletion of CCR2 (a specific receptor of CCL2) impaired thrombus resolution with the reduced recruitment of $\mathrm{F} 4 / 80^{+}$ macrophages (14). These observations implied that the CCL2-CCR2 axis could promote thrombus resolution by inducing macrophage infiltration into thrombus. Given the observations that IL-6 could up-regulate CCL2 expression in macrophages $(32,33)$, we determined intrathrombotic CCL2 expression. Macrophages were identified as a major source of CCL2 in thrombus, and intrathrombotic CCL2 expression was significantly attenuated in IVC-ligated $\mathrm{Il}^{-/-}$mice compared with IVC-ligated WT mice. Thus, IL-6 can induce macrophages to express CCL2, which can boost the infiltration of macrophages, the cell component crucially involved in thrombus resolution.
No significant differences were observed in APTT and PTT between WT and $I l 6^{-/-}$mice, indicating that coagulation dysfunction can account for the different phenotype of these two strains. On the contrary, $I l 6^{-/-}$mice exhibited reduced intrathrombotic gene expression of Plau, a major plasminogen activator, whereas IL-6 augmented Plau mRNA expression in macrophages, a major cell type present in thrombus. Tissue- and urokinase-type plasminogen activators can promote the generation from plasminogen to plasmin, which has an important role in clotting, fibrinolysis, inflammatory angiogenesis, and tissue remodeling (34). Reflecting the crucial roles of the balance between plasminogen activators and inhibitors in proteolytic and anti-proteolytic activities, the lack of PLAU markedly impaired thrombus resolution (35). Thus, it is probable that IL-6 can promote thrombus resolution by enhancing Plau expression in macrophages.

Venous thrombus is replaced by deposited collagen as time passes (26), and therefore, thrombus resolution requires collagen 

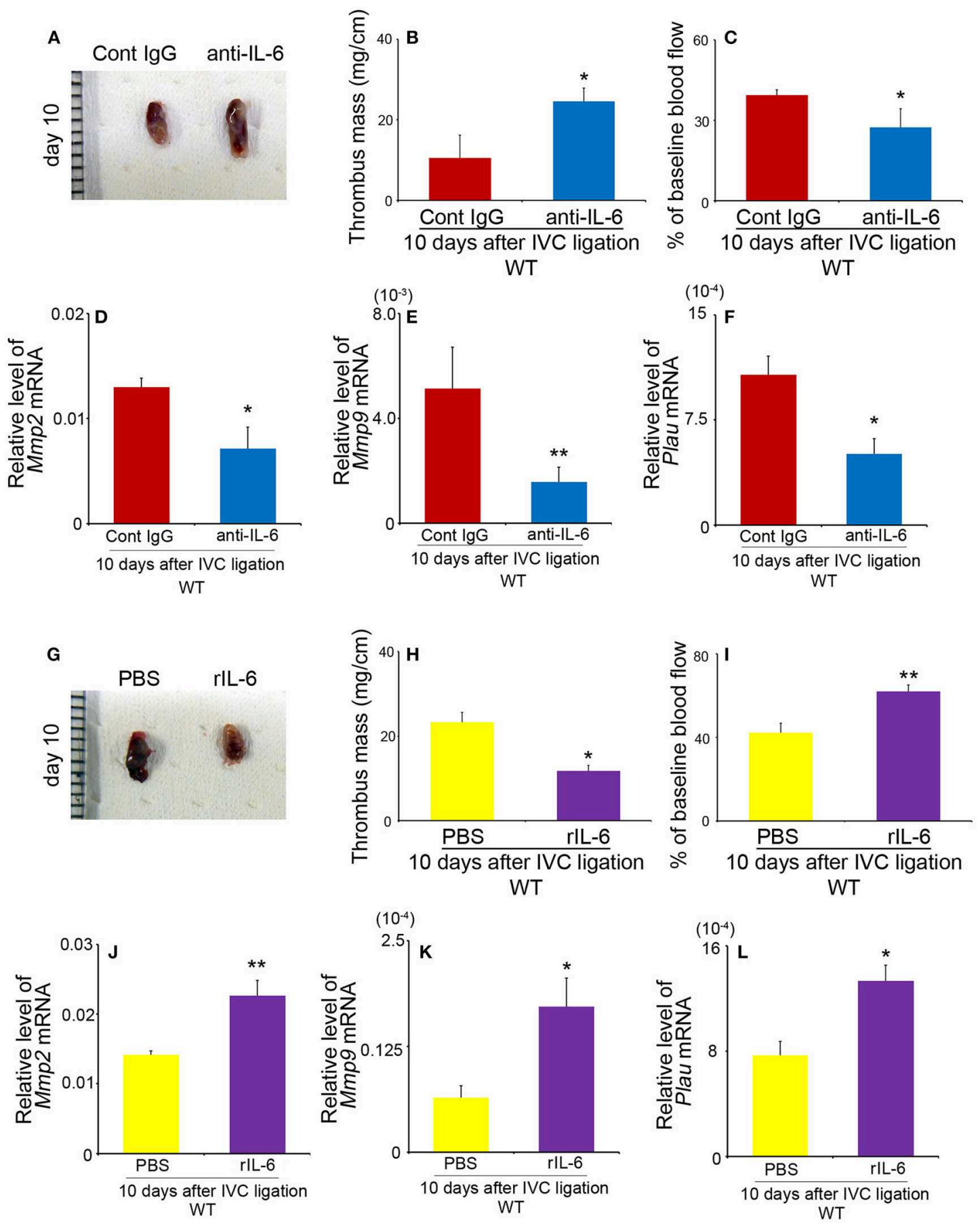

FIGURE 5 | The effects of anti-IL-6 antibody (Ab) and recombinant murine IL-6 (rlL-6) in wild-type (WT) mice on thrombus resolution. (A-F) WT mice were intraperitoneally administered with anti-IL-6 as described in section Materials and Methods. (A) Macroscopic appearance of venous thrombi obtained from WT mice treated with anti-IL-6 Ab or control IgG at 10 days after inferior vena cava (IVC) ligation. Representative results from six independent animals are shown here. Thrombus weights $\mathbf{( B )}$ and thrombosed blood flow $\mathbf{( C )}$ were measured at 10 days after IVC ligation. All values represent the mean $\pm \mathrm{SEM}\left(n=6\right.$ animals). ${ }^{*} p<0.05$ vs. control IgG. (D-F) Intrathrombotic gene expression of Mmp2 (D), Mmp9 (E), and Plau (F) after IVC ligation. Each gene expression was determined by real-time reverse transcription (RT)-PCR as described in section Materials and Methods. All values represent the mean $\pm \mathrm{SEM}\left(n=6\right.$ animals). ${ }^{*} p<0.05$, ${ }^{\star *} p<0.01$, control Ig vs. anti-IL-6. (G-L) WT mice were intraperitoneally administered with rlL-6 as described in section Materials and Methods. (G) Macroscopic appearance of venous thrombi obtained from WT mice treated with rIL-6 or phosphate-buffered saline (PBS) at 10 days after IVC ligation. Representative results from six independent animals are shown here. Thrombus weights $\mathbf{( H )}$ and thrombosed blood flow $\mathbf{( I )}$ were measured at 10 days after IVC ligation. All values represent the mean \pm SEM $(n=$ 6 animals). ${ }^{*} p<0.05,{ }^{* \star} p<0.01$, PBS vs. rlL-6. (J-L) Intrathrombotic gene expression of Mmp2 (J), Mmp9 (K), and Plau (L) after IVC ligation. Each gene expression was determined by real-time RT-PCR as described in section Materials and Methods. All values represent the mean \pm SEM $\left(n=6\right.$ animals). ${ }^{\star} p<0.05$, ${ }^{\star \star} p<0.01$, control PBS vs. rIL-6. 

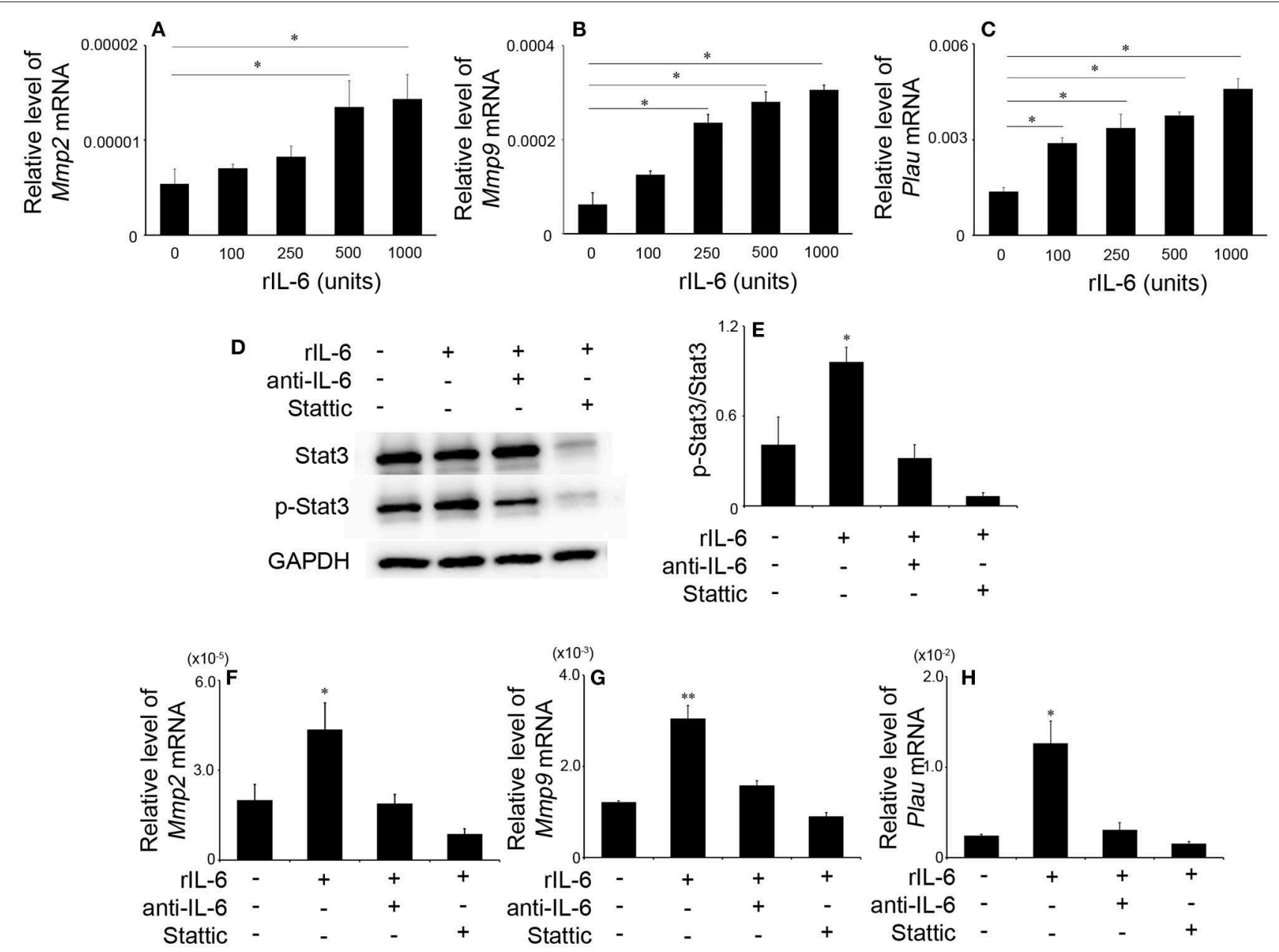

FIGURE 6 | The effects of recombinant murine IL-6 (rlL-6) on the gene expression of Mmp2, Mmp9, and Plau and on Stat3 signaling in peritoneal macrophages. Peritoneal macrophages were obtained from wild-type (WT) mice and were stimulated as described in section Materials and Methods. The gene expression of Mmp2 (A), Mmp9 (B), and Plau (C) was analyzed by real-time reverse transcription (RT)-PCR. All values represent the mean \pm SEM $\left(n=6\right.$ independent experiments). ${ }^{*} p<$ 0.05, vs. no stimulation. (D) Western blotting analysis using anti-GAPDH pAbs confirmed that an equal amount of protein was loaded onto each lane. Representative results from six independent experiments are shown here. (E) The ratios of p-Stat3/Stat3 were densitometrically determined and are shown. All values represent means \pm SEM ( $n=4$ independent experiments). (F-H) The effects of anti-IL-6 or Stattic on IL-6-induced gene expression of Mmp2 (F), Mmp9 (G), and Plau (H). Each gene expression was analyzed by real-time RT-PCR. All values represent the mean \pm SEM ( $n=4$ independent experiments). ${ }^{\star} p<0.05$; ${ }^{* \star} p<0.01$, vs. no stimulation.

degradation. $I 6^{-/-}$mice displayed enhanced intrathrombotic collagen contents than did WT mice, indicating that IL6 deficiency can increase collagen synthesis or decrease collagenolysis. The latter possibility was supported by our present observations that $\mathrm{Il}^{-/-}$mice exhibited reduced intrathrombotic expression of MMP-2 and MMP-9, the enzymes that have important roles in collagen turnover during thrombus resolution owing to their potent collagenolysis activities $(14,17)$. Moreover, evidence is accumulating to indicate that $M m p 2$ and $M m p 9$ expression can be enhanced by inflammatory cytokines such as IL-1, TNF- $\alpha$, and IL-6 (33, 36-38). Consistently, we also revealed that IL-6 can augment $M m p 2$ and $M m p 9$ gene expression in peritoneal macrophages and that these effects were canceled by anti-IL-6 antibody. Thus, IL-6 could be a potent inducer for MMP-2 and MMP-9 in intrathrombotic macrophages.

Several distinct signaling pathways have been presumed to be involved in MMP gene expression (39-41). IL-6 can utilize
Stat3 and other MAP kinases to transduce its intracellular signals (19). However, we unraveled that IL-6 significantly enhanced the phosphorylation of Stat3 but not other MAP kinases such as ERK, JNK, and p38, thereby enhancing the mRNA expression of $M m p 2, M m p 9$, and Plau in macrophages. Moreover, the Stattic, a Stat3 inhibitor, significantly suppressed IL-6-induced the gene expression of these molecules. Thus, these observations provided the evidence to indicate the crucial involvement of the IL-6/Stat3 signal pathways in venous thrombus resolution through MMP-2, MMP-9, and PLAU.

There are still discrepancies in pathophysiological roles of IL6 in DVT. Clinically, several inflammatory mediators including IL-6 are proposed to increase the risk of DVT in various types of pathological conditions such as surgery, obesity, cystic fibrosis, sepsis, systemic infection, cancer, inflammatory bowel disease, and lupus (42). Cancer patients, particularly, show a four-fold increased risk for DVT depending on multiple factors 
such as patient conditions, tumor characteristics, and treatment modalities (43). The presence of the tumor may affect the host coagulation system, and anticancer treatments also increase the risk of venous thromboembolism (VTE) in cancer patients (43). Accumulating evidence implied the close association of IL- 6 with the incidence of DVT in cancer patients (44-46). Malaponte and colleagues demonstrated that IL-6 levels in plasma and monocyte samples were higher in cancer patients with DVT than in those without DVT (45). In line with this observation, Stone et al. showed that tumor-derived IL- 6 promoted thrombocytosis through the induction of hepatic thrombopoietin, eventually increasing the incidences of DVT in a mouse model of ovarian cancer (44). These observations suggested that IL-6 could promote thrombus formation through an increase of coagulation activity. On the contrary, we observed that IL-6 administration had few effects on coagulation functions.

Thrombosis results from the imbalance caused by increases of formation rate and/or a delay of resolution. However, the previous clinical study on cancer patients did not examine the relationship between IL- 6 and resolution-related molecules (44-46). From our observations, IL-6 can promote thrombus resolution by regulating macrophage recruitment via the upregulation of CCL2 and enhancing their expression of MMPs and PLAU in thrombus. In line with this, Malaponte (46) found a positive correlation between IL-6 and MMP-9 plasma concentrations in both DVT and non-DVT cancer patients. These observations may imply that IL-6 expression may be enhanced in the presence of DVT to accelerate thrombus resolution in cancer patients. This assumption has been strengthened by the observations that the administration of exogenous IL- 6 accelerated thrombus resolution in WT mice after the IVC ligation.

Anti-coagulant therapy such as warfarin is mainly employed against DVT to prevent pulmonary thromboembolism (PTE), but it increases the incidence of bleeding complications. On the contrary, the administration of IL- 6 had few effects on coagulation functions. It is clinically important that IL6 administration under the presence of thrombus could reduce thrombus size. Our observations implied that IL-6 administration after thrombus formation might be effective for

\section{REFERENCES}

1. Aggarwal A, Fullam L, Brownstein AP, Maynard GA, Ansell J, Varga EA, et al. Deep vein thrombosis (DVT) and pulmonary embolism (PE): awareness and prophylaxis practices reported by patients with cancer. Cancer Invest. (2015) 33:405-10. doi: 10.3109/07357907.2015.1048871

2. Saleh J, El-Othmani MM, Saleh KJ. Deep vein thrombosis and pulmonary embolism considerations in orthopedic surgery. Orthop Clin North Am. (2017) 48:127-35. doi: 10.1016/j.ocl.2016.12.003

3. Bagot CN, Arya R. Virchow and his triad: a question of attribution. $\mathrm{Br} J$ Haematol. (2008) 143:180-90. doi: 10.1111/j.1365-2141.2008.07323.x

4. Shebuski RJ, Kilgore KS. Role of inflammatory mediators in thrombogenesis. J Pharmacol Exp Ther. (2002) 300:729-35. doi: 10.1124/jpet.300.3.729

5. Lambert MP, Sachais BS, Kowalska MA. Chemokines and thrombogenicity. Thromb Haemost. (2007) 97:722-9. doi: 10.1160/TH07-01-0046

6. Wakefield TW, Myers DD, Henke PK. Mechanisms of venous thrombosis and resolution. Arterioscler Thromb Vasc Biol. (2008) 28:387-91. doi: 10.1161/ATVBAHA.108.162289 the reduction of thrombus size, because intrathrombotic IL6 protein levels started to increase at 5 days after the IVC ligation. Thus, IL-6 may be a target molecule to induce DVT resolution, although more work on human clinical conditions is warranted.

\section{DATA AVAILABILITY STATEMENT}

All datasets generated for this study are included in the article/Supplementary Material.

\section{ETHICS STATEMENT}

The animal study was reviewed and approved by Wakayama Medical University Animal Care and Use Committees (no. 879).

\section{AUTHOR CONTRIBUTIONS}

TK and NM formulated the hypothesis and initiated and organized the study. $\mathrm{MN}$ and YI performed the main experimental work and analyzed the data. AK, YK, ATar, MO, and ATan helped with some experimental procedures. TK and NM oversaw the experiments, analyzed the data, provided the main funding for the research, and prepared the final manuscript.

\section{FUNDING}

This study was financially supported in part by Grants-in-Aids for Scientific Research (TK and MN) from the Japan Society for the Promotion of Science (JSPS) and Grant-in-Aids for Medical Research (TK) from Mitsui Life Social Welfare Foundation and the Uehara Memorial Foundation.

\section{SUPPLEMENTARY MATERIAL}

The Supplementary Material for this article can be found online at: https://www.frontiersin.org/articles/10.3389/fimmu. 2019.03150/full\#supplementary-material
7. Wakefield TW, Strieter RM, Wilke CA, Kadell AM, Wrobleski SK, Burdick $\mathrm{MD}$, et al. Venous thrombosis-associated inflammation and attenuation with neutralizing antibodies to cytokines and adhesion molecules. Arterioscler Thromb Vasc Biol. (1995) 15:258-68. doi: 10.1161/01.ATV.15.2.258

8. Deatrick KB, Luke CE, Elfline MA, Sood V, Baldwin J, Upchurch GR Jr, et al. The effect of matrix metalloproteinase 2 and matrix metalloproteinase 2/9 deletion in experimental post-thrombotic vein wall remodeling. J Vasc Surg. (2013) 58:1375-84. doi: 10.1016/j.jvs.2012.11.088

9. Engelmann B, Massberg S. Thrombosis as an intravascular effector of innate immunity. Nat Rev Immunol. (2013) 13:34-45. doi: 10.1038/nri3345

10. Saha P, Humphries J, Modarai B, Mattock K, Waltham M, Evans CE, et al. Leukocytes and the natural history of deep vein thrombosis: current concepts and future directions. Arterioscler Thromb Vasc Biol. (2011) 31:506-12. doi: 10.1161/ATVBAHA.110.213405

11. Henke PK, Varma MR, Moaveni DK, Dewyer NA, Moore AJ, Lynch EM, et al. Fibrotic injury after experimental deep vein thrombosis is determined by the mechanism of thrombogenesis. Thromb Haemost. (2007) 98:1045-55. doi: 10.1160/TH07-03-0190 
12. Stewart GJ. Neutrophils and deep venous thrombosis. Haemostasis. (1993) 1:127-40. doi: 10.1159/000216922

13. Tan P, Luscinskas FW, Homer-Vanniasinkam S. Cellular and molecular mechanisms of inflammation and thrombosis. Eur J Vasc Endovasc Surg. (1999) 17:373-89. doi: 10.1053/ejvs.1998.0759

14. Henke PK, Pearce CG, Moaveni DM, Moore AJ, Lynch EM, Longo C, et al. Targeted deletion of CCR2 impairs deep vein thombosis resolution in a mouse model. J Immunol. (2006) 177:3388-97. doi: 10.4049/jimmunol.177.5.3388

15. Henke PK, Varga A, De S, Deatrick CB, Eliason J, Arenberg DA, et al. Deep vein thrombosis resolution is modulated by monocyte CXCR2-mediated activity in a mouse model. Arterioscler Thromb Vasc Biol. (2004) 24:1130-7. doi: 10.1161/01.ATV.0000129537.72553.73

16. Humphries J, McGuinness CL, Smith A, Waltham M, Poston R, Burnand KG. Monocyte chemotactic protein-1 (MCP-1) accelerates the organization and resolution of venous thrombi. J Vasc Surg. (1999) 30:894-9. doi: 10.1016/S0741-5214(99)70014-5

17. Nosaka M, Ishida Y, Kimura A, Kuninaka Y, Inui M, Mukaida N, et al. Absence of IFN- $\gamma$ accelerates thrombus resolution through enhanced MMP9 and VEGF expression in mice. J Clin Invest. (2011) 121:2911-20. doi: 10.1172/JCI40782

18. Nosaka M, Ishida Y, Kimura A, Kuninaka Y, Taruya A, Furuta M, et al. Contribution of the TNF- $\alpha$ (Tumor Necrosis Factor- $\alpha$ )-TNFRp55 (tumor necrosis factor receptor p55) axis in the resolution of venous thrombus. Arterioscler Thromb Vasc Biol. (2018) 38:2638-50. doi: 10.1161/ATVBAHA.118.311194

19. Murakami M, Kamimura D, Hirano T. Pleiotropy and specificity: insights from the interleukin 6 family of cytokines. Immunity. (2019) 50:812-31. doi: 10.1016/j.immuni.2019.03.027

20. Tanaka T, Narazaki M, Kishimoto T. IL-6 in inflammation, immunity, and disease. Cold Spring Harb Perspect Biol. (2014) 6:a016295. doi: 10.1101/cshperspect.a016295

21. Soehnlein O, Lindbom L. Phagocyte partnership during the onset and resolution of inflammation. Nat Rev Immunol. (2010) 10:427-39. doi: $10.1038 /$ nri2779

22. Lin ZQ, Kondo T, Ishida Y, Takayasu T, Mukaida N. Essential involvement of IL-6 in the skin wound-healing process as evidenced by delayed wound healing in IL-6-deficient mice. J Leukoc Biol. (2003) 73:713-21. doi: 10.1189/jlb.0802397

23. Nosaka M, Ishida Y, Kimura A, Hama M, Kawaguchi T, Yamamoto H, et al. Immunohistochemical detection of intrathrombotic IL-6 and its application to thrombus age estimation. Int J Legal Med. (2015) 129:1021-5. doi: 10.1007/s00414-015-1147-9

24. Kopf M, Baumann H, Freer G, Freudenberg M, Lamers M, Kishimoto T, et al. Impaired immune and acute-phase responses in interleukin-6-deficient mice. Nature. (1994) 368:339-42. doi: 10.1038/368339a0

25. Kimura A, Ishida Y, Wada T, Hisaoka T, Morikawa Y, Sugaya T, et al. The absence of interleukin- 6 enhanced arsenite-induced renal injury by promoting autophagy of tubular epithelial cells with aberrant extracellular signal-regulated kinase activation. Am J Pathol. (2010) 176:4050. doi: 10.2353/ajpath.2010.090146

26. Nosaka M, Ishida Y, Kimura A, Kondo T. Time-dependent organic changes of intravenous thrombi in stasis-induced deep vein thrombosis model and its application to thrombus age determination. Forensic Sci Int. (2010) 195:143-7. doi: 10.1016/j.forsciint.2009.12.008

27. Varma MR, Varga AJ, Knipp BS, Sukheepod P, Upchurch GR, Kunkel SL, et al. Neutropenia impairs venous thrombosis resolution in the rat. J Vasc Surg. (2003) 38:1090-8. doi: 10.1016/S0741-5214(03)00431-2

28. Ali T, Humphries J, Burnand K, Sawyer B, Bursill C, Channon K, et al. Monocyte recruitment in venous thrombus resolution. J Vasc Surg. (2006) 43:601-8. doi: 10.1016/j.jvs.2005.10.073

29. Luther N, Shahneh F, Brähler M, Krebs F, Jäckel S, Subramaniam S, et al. Innate effector-memory $\mathrm{T}$-cell activation regulates post-thrombotic vein wall inflammation and thrombus resolution. Circ Res. (2016) 119:1286-95. doi: 10.1161/CIRCRESAHA.116.309301

30. Nosaka M, Ishida Y, Kimura A, Kondo T. Time-dependent appearance of intrathrombus neutrophils and macrophages in a stasis-induced deep vein thrombosis model and its application to thrombus age determination. Int $J$ Legal Med. (2009) 123:235-40. doi: 10.1007/s00414-009-0324-0
31. Henke PK, Wakefield T. Thrombus resolution and vein wall injury: dependence on chemokines and leukocytes. Thromb Res. (2009) 123(Suppl. 4):S72-8. doi: 10.1016/S0049-3848(09)70148-3

32. Wang X, Yang X, Tsai Y, Yang L, Chuang KH, Keng PC, et al. IL6 Mediates macrophage infiltration after irradiation via up-regulation of CCL2/CCL5 in non-small cell lung cancer. Radiat Res. (2017) 187:50-9. doi: $10.1667 /$ RR14503.1

33. Tieu BC, Lee C, Sun H, Lejeune W, Recinos A III, Ju X, et al. An adventitial IL-6/MCP1 amplification loop accelerates macrophage-mediated vascular inflammation leading to aortic dissection in mice. J Clin Invest. (2009) 119:3637-51. doi: 10.1172/JCI38308

34. Andreasen PA, Kjoller L, Christensen L, Duffy MJ. The urokinase-type plasminogen activator system in cancer metastasis: a review. Int J Cancer. (1997) 72:1-22. doi: 10.1002/(SICI)1097-0215(19970703)72:1<1::AIDIJC1>3.0.CO;2-Z

35. Singh I, Burnand KG, Collins M, Luttun A, Collen D, Boelhouwer B, et al. Failure of thrombus to resolve in urokinase-type plasminogen activator gene-knockout mice: rescue by normal bone marrow-derived cells. Circulation. (2003) 107:869-75. doi: 10.1161/01.CIR.0000050149.2 2928.39

36. Saren P, Welgus HG, Kovanen PT. TNF- $\alpha$ and IL-1 $\beta$ selectively induce expression of $92-\mathrm{kDa}$ gelatinase by human macrophages. J Immunol. (1996) 157:4159-65

37. Han YP, Tuan TL, Wu H, Hughes M, Garner WL. TNF- $\alpha$ stimulates activation of pro-MMP2 in human skin through NF-( $)$ B mediated induction of MT1MMP. J Cell Sci. (2001) 114:131-9.

38. Kothari P, Pestana R, Mesraoua R, Elchaki R, Khan KM, Dannenberg AJ, et al. IL-6-mediated induction of matrix metalloproteinase- 9 is modulated by JAKdependent IL-10 expression in macrophages. J Immunol. (2014) 192:349-57. doi: 10.4049/jimmunol.1301906

39. Clark IM, Swingler TE, Sampieri CL, Edwards DR. The regulation of matrix metalloproteinases and their inhibitors. Int J Biochem Cell Biol. (2008) 40:1362-78. doi: 10.1016/j.biocel.2007.12.006

40. Yan C, Boyd DD. Regulation of matrix metalloproteinase gene expression. J Cell Physiol. (2007) 211:19-26. doi: 10.1002/jcp.20948

41. Reuben PM, Cheung HS. Regulation of matrix metalloproteinase (MMP) gene expression by protein kinases. Front Biosci. (2006) 11:1199-215. doi: $10.2741 / 1873$

42. Branchford BR, Carpenter SL. The role of inflammation in venous thromboembolism. Front Pediatr. (2018) 6:142. doi: 10.3389/fped.201 8.00142

43. Hisada Y, Geddings JE, Ay C, Mackman N. Venous thrombosis and cancer: from mouse models to clinical trials. J Thromb Haemost. (2015) 13:1372-82. doi: $10.1111 /$ jth.13009

44. Stone RL, Nick AM, McNeish IA, Balkwill F, Han HD, Bottsford-Miller J, et al. Paraneoplastic thrombocytosis in ovarian cancer. N Engl J Med. (2012) 366:610-8. doi: 10.1056/NEJMoa1110352

45. Malaponte G, Signorelli SS, Bevelacqua V, Polesel J, Taborelli M, Guarneri $\mathrm{C}$, et al. Increased levels of NF-кB-dependent markers in cancerassociated deep venous thrombosis. PLoS ONE. (2015) 10:e0132496. doi: 10.1371/journal.pone.0132496

46. Malaponte G, Polesel J, Candido S, Sambataro D, Bevelacqua V, Anzaldi $\mathrm{M}$, et al. IL-6-174G $>\mathrm{C}$ and MMP-9-1562 C > T polymorphisms are associated with increased risk of deep vein thrombosis in cancer patients. Cytokine. (2013) 62:64-9. doi: 10.1016/j.cyto.201 3.02.017

Conflict of Interest: The authors declare that the research was conducted in the absence of any commercial or financial relationships that could be construed as a potential conflict of interest.

Copyright (C) 2020 Nosaka, Ishida, Kimura, Kuninaka, Taruya, Ozaki, Tanaka, Mukaida and Kondo. This is an open-access article distributed under the terms of the Creative Commons Attribution License (CC BY). The use, distribution or reproduction in other forums is permitted, provided the original author(s) and the copyright owner(s) are credited and that the original publication in this journal is cited, in accordance with accepted academic practice. No use, distribution or reproduction is permitted which does not comply with these terms. 